\title{
OS ATORES SUBNACIONAIS NO MERCOSUL: 0 CASO DAS PAPELERAS
}

\section{Marcelo de Almeida Medeiros Miriam Gomes Saraiva}

\begin{abstract}
"Nos, los representantes de las Provincias Unidas de Sud América, reunidos em Congreso General, invocando al Eterno que preside el Universo, en el nombre y por la autoridad de los pueblos que representamos, protestando al cielo, a lãs naciones y a los hombres todos Del globo, la justicia que regla nuestros votos: declaramos solemnemente a la faz de la tierra, que es voluntad unânime e indubitable de estas Provincias romper los vínculos que las ligan a los reys de Espana, recuperar los derechos de que fueron despojadas, e investirse del alto carácter de uma nación livre e independiente..." Declaración de la Independencia. ${ }^{1}$
\end{abstract}

\section{Introdução}

A constante e progressiva participação de governos subnacionais na esfera internacional chama atenção para uma nova dimensão das relações internacionais que começou a ser estudada há pouco tempo. As razões para esta implicação de governos subnacionais no cenário externo são vinculadas tanto às mudanças que ocorreram na esfera internacional, às reformas no interior dos Estados, quanto às modificações que têm lugar no comportamento dos governos subnacionais.

Em termos internacionais, a globalização contribui para uma maior interpenetração das fronteiras por temas internacionais, ou para a diluição da fronteira entre o nacional

\footnotetext{
${ }^{1}$ Declaração de Independência das Províncias Unidas do Rio da Prata, estabelecida em 9 de julho de 1816 na cidade de San Miguel de Tucumán.
} 
e o internacional em diversas áreas. A transnacionalização e a interdependência complexa (Keohane, 2001), próprias deste processo, favorecem a criação de novos canais de vinculação e diversidade de atores que atuam nas relações internacionais, assim como a variedade também de temas abordados (Colacrai e Zubelzú, 2004). Neste novo cenário, os limites próprios da política externa estatal tradicional são superados, e a variedade de atores com dimensões e estilos diferentes que participam das ações internacionais experimentam um aumento significativo. Existe uma concorrência regional em âmbito tanto continental quanto global por mercados e investimentos, assim como organizações sediadas em países desenvolvidos que buscam implementar uma política de cooperação direcionada diretamente a governos subnacionais e a sociedades civis locais. Este movimento vem abrindo espaço para uma participação cada vez mais significativa de atores subnacionais.

Nos marcos dos Estados, há, em termos gerais, uma modificação na divisão de responsabilidade entre o governo central e os governos subnacionais. Em função das mudanças que têm lugar no comércio internacional, a capacidade do Estado de promover o desenvolvimento nacional e regional sofre uma deterioração. Os instrumentos para o governo central estabelecer relações de intercâmbio com suas províncias através de políticas de benefícios ou políticas regionais distributivas enfrentam obstáculos e perdem efetividade (Keating, 2004, p. 53). A competitividade nacional vis a vis o exterior recebe mais destaque que um equilíbrio entre as regiões de um mesmo Estado.

A nível sub-regional, este novo cenário interno torna mais forte a concorrência inter-regional por mercados e insumos para o seu desenvolvimento, e leva os governos subnacionais a buscar mais diretamente os benefícios da economia global. Desde uma perspectiva regional, políticos mais empreendedores buscam, através de iniciativas próprias do 
cenário de competição, consolidar suas próprias regiões ou nelas reforçar suas respectivas posições políticas dentro das mesmas (Keating, 2004, p. 53). As regiões atuam então tanto nos marcos dos Estados, quanto nos marcos de regimes transnacionais e de uma economia global, assumindo um papel de maior protagonismo na esfera internacional.

Neste quadro, Colacrai (2005, p. 319) chama a atenção para províncias/regiões que se comportam como "Estados comercialistas" atuando diretamente na economia internacional, independentemente do Estado matriz ao qual pertencem: o "region state". ${ }^{2}$

Este conjunto de ações de governos subnacionais é chamado por Keating (2004) de paradiplomacia. A paradiplomacia é resultado do aumento do número de atores vinculados a assuntos internacionais e é diferente da diplomacia convencional de um Estado. É por si muito mais delimitada, oportunista e experimental, assim como sujeita aos erros em iniciativas orientadas para atingir resultados mais favoráveis em uma relação de custo e benefício (Keating, 2004, p. 66).

A paradiplomacia tem como característica também uma maior participação da sociedade civil e de setores privados, e causa muitas vezes preocupações nos ministérios de relações exteriores que temem perder o controle de uma área na qual, até pouco tempo, concentravam o poder formulador e, sobretudo, implementador das políticas. Suas relações com o Estado nacional são limitadas pelas características constitucionais e pela esfera política de cada Estado, assim como não podem entrar em atrito com as linhas gerais de atuação externa deste Estado. Keating apresenta três motivações mais frequentes para a paradiplomacia. As motivações econômicas, que levam um governo subna-

2 O termo "Estado comercialista" é de Rosecrance, 1986, citado por Colacrai e Zubelzú (2004). 
cional a buscar investimentos, mercados e tecnologia. As motivações políticas, que utilizam o cenário internacional como plataforma de construção regional interna ou buscam influenciar a opinião pública em países estrangeiros sobre determinado tema. Por fim, a motivação cultural, que faz com que regiões com cultura própria busquem recursos e apoio no cenário externo. Estes movimentos promovem os interesses paroquiais, vinculam diferentes sociedades e institucionalizam novas formas de cooperação. Estes vínculos são muitas vezes transfronteiriços, mas também podem se dar em escala global.

A implicação de governos subnacionais nas relações internacionais pode ser explicada também a partir do conceito mais amplo de constituent diplomacy (Medeiros, 2006). Neste caso, governos subnacionais buscam ampliar seus espaços de participação no processo decisório sobre questões externas e interagem junto ao governo central buscan80 do influenciar sobre os rumos da política comercial ou da política externa de um Estado. Esta interação pode se dar através de secretarias especializadas de governos regionais ou de canais ad hoc. Segundo Lima (2000, p. 87):

"quando as consequências da política externa são distributivas, no sentido de que custos e benefícios não se distribuem igualmente na sociedade, a política doméstica tem influência na formação da política externa”.

A internacionalização da economia e a abertura comercial contribuem para a internacionalização da agenda doméstica com a incorporação de temas antes limitados ao Executivo nas preocupações da esfera legislativa e de setores da sociedade civil. A abertura da economia favorece a politização dos temas externos, em função dos impactos distributivos produzidos. A consolidação democrática também fomenta a politização da política externa em geral. 
Assim, durante os anos 1990, ambos os processos desafiam a formulação e decisões tradicionais de política exterior. $\mathrm{O}$ resultado da diplomacia comercial e da política de integração regional são exemplos de negociações que produzem impactos distributivos internamente.

A proposta deste artigo é analisar o conflito resultante da construção de usinas Papeleras, de uma conjunção entre o governo nacional argentino, o governo provincial de Entre Ríos e setores da sociedade civil de Gualeguaychú contra o governo uruguaio, à luz deste debate.

\section{Os atores subnacionais no Mercosul e na Argentina}

Nos marcos do Mercosul, a participação de atores subnacionais é bastante limitada. O caráter intergovernamental do bloco contribui para seu padrão básico de negociação ser entre governos nacionais. Sua baixa institucionalidade limita as possibilidades de existência de mecanismos de compensação importantes para as dimensões subnacionais, assim como dificulta a consolidação de um mecanismo eficiente de solução de controvérsias. ${ }^{3}$ A não existência de mecanismos de compensação impede que as regiões prejudicadas em função dos impactos distributivos do processo de integração reduzam suas perdas. Nenhuma instância de poder assume a tarefa de "evitar ou minimizar as consequências perversas do processo de integração sobre as esferas subnacionais de governo" (Mariano e Barreto, 2004, p. 31). A ausência de instâncias regionais orientadas para este problema amplia e politiza muitas vezes contendas inicialmente restritas ao campo econômico; os conflitos não encontram instrumentos adequados para resolvê-los, ficando a cargo dos governos nacionais. Neste quadro, as províncias/regiões estagnadas em seu desenvolvimento têm como alternativas

\footnotetext{
${ }^{3}$ Os mecanismos recém-criados ainda não estão consolidados. O artigo de Mariano e Barreto (2004) dá bons insights sobre o tema.
} 
atuar com vistas a conseguirem políticas mais favoráveis a seus interesses, ou exercer pressões sobre o governo nacional para conseguir algum tipo de compensação.

A prática mais frequente de atuação de poderes subnacionais é, porém, de cooperação direta sub-regional e da interação com províncias/regiões de países vizinhos. Esta interação é impulsionada por motivos variados e, em geral, caracteriza-se pela diversidade de contatos, dependências recíprocas e múltiplas, trocas comerciais e laços culturais. Envolvem diversos agentes econômicos privados e da sociedade civil através de canais próprios de atuação.

Neste processo, apesar dos limites impostos pelo caráter intergovernamental do bloco, a participação de poderes subnacionais no Mercosul também experimenta um aumento progressivo através de dois canais diferentes. Primeiro, fora dos marcos formais do Mercosul, desenvolvem-se dois mecanismos de atuação para unidades subna82 cionais: o Crecenea-Codesul, ${ }^{4}$ que é um mecanismo que articula governos do norte argentino e do sul e centrooeste do Brasil, com vistas a resolver problemas objetivos, e questiona o pacto federativo ao pedir maior participação para as unidades subnacionais; e a Rede de Mercocidades que é criada em 1995 com o objetivo de buscar seu reconhecimento na estrutura do Mercosul. Essa rede busca: a possibilidade de acessar à decisão em suas áreas de competência; criar e impulsionar projetos e ações de interesse comum de caráter intermunicipal; promover mecanismos de comunicação entre cidades para intercâmbio de infor-

\footnotetext{
${ }^{4}$ A Comissão Regional de Comércio Exterior do NEA (Crecenea) foi criada de comum acordo entre as províncias de Chaco, Corrientes, Entre Ríos, Formosa, Misiones e Santa Fé, com o intuito de impulsionar a integração do noreste argentino (NEA) com os estados fronteiriços vizinhos. O Sistema Conselho de Desenvolvimento e Integração Sul - Banco Regional de Desenvolvimento do Extremo Sul (Codesul - BRDE) -, foi criado, em 1961, através de um convênio entre os estados do Rio Grande do Sul, Santa Catarina e Paraná. Em 1992, o estado do Mato Grosso do Sul passou a integrar o Conselho.
} 
mações. Segundo, como parte do organograma do Mercosul, em dezembro de 2004 foi criado o Foro Consultivo de Municípios, Estados, Províncias e Departamentos do Mercosul, mas que ainda está em fase de regulamentação de seu funcionamento.

No caso da Argentina, em 1992 é implementada uma reforma na Chancelaria com o fito de viabilizar a cooperação entre organismos de diferentes poderes de Estado, incluindo as esferas nacional, provincial e municipal. ${ }^{5}$ Com este objetivo, foi criada a Subsecretaría de Relaciones Institucionales, que foi dividida em quatro direções, sendo a Dirección de Asuntos Federales a encarregada de tratar com governos provinciais e organismos regionais. Em 1999, as quatro convergiram na Dirección General de Relaciones Institucionales.

Este mecanismo abre espaços para a implementação de uma constituent diplomacy ${ }^{6}$ como canal para que as elites provinciais passem a formular reivindicações e exercer pressão sobre as estratégias externas. Ele institucionaliza os canais através dos quais os governos provinciais podem buscar recursos de fomento das economias regionais sem atritos com o Executivo nacional. E, muitas vezes, chegam a influir na política externa nacional.

A reforma constitucional de 1994, por sua vez, abre espaços para as atuações internacionais das Províncias, ou para a paradiplomacia. De acordo com o artigo 124 da Constituição nacional, as Províncias ficam autorizadas a criar regiões mais amplas conectadas para o desenvolvimento e a assinar acordos internacionais de integração sub-regional com outras províncias, desde que não entrem em choque

\footnotetext{
${ }^{5}$ Decreto n.1190 M 133, citado por Colacrai e Zubelzú (2004, p. 322).

6 "O termo constituent diplomacy tem intenção de ser um descritor neutro, que evite a implicação de que as atividades dos governos constituintes são necessariamente inferiores, subsidiárias ou suplementares da alta política da diplomacia do Estadonação" (Kincaid, 2001, p. 74).
} 
com a política exterior nacional. ${ }^{7}$ Trata-se basicamente de convênios de cooperação sobre temas específicos, que procuram resolver questões em geral pragmáticas. Com isso, os governos provinciais têm competência para atuar no cenário externo, assim como gerir financiamentos oriundos do exterior. Desde a perspectiva das Províncias, algumas sugerem em suas próprias constituições atributos no que diz respeito a questões internacionais. ${ }^{8}$

Segundo Colacrai e Zubelzú (2004), este avanço na área de relações exteriores das Províncias deve-se não somente a tendências globais da interdependência e da transnacionalização, mas também à opção de abertura do governo de Carlos Menem. ${ }^{9}$ Neste processo, simultaneamente ao plano econômico de convertibilidade, muitas Províncias buscam por conta própria mercados e investimentos assumindo um comportamento "mercantilista". A democratização também dá condições para que este movimento seja posto em marcha.

84 Atualmente existem na Argentina algumas formas institucionalizadas de cooperação sub-regional. Primeiro, e em termos internos, algumas Províncias buscam, atendendo ao Art.124 da Constituição nacional, conformar regiões maiores como parte de uma integração sub-regional. Em 1998, é

\footnotetext{
7 "As províncias poderão criar regiões para o desenvolvimento econômico e social, estabelecer órgãos com faculdades para o cumprimento de seus fins, e poderão também celebrar convênios internacionais desde que não sejam incompatíveis com a política exterior da Nação e não afetem as faculdades delegadas ao Governo federal e ao crédito público da Nação; com conhecimento do Congresso Nacional".

8 A Constituição de Entre Ríos, por exemplo, é reveladora quando assinala em seu artigo 1.: "La Provincia de Entre Ríos, como parte integrante de la Nación Argentina, organiza su gobierno bajo la forma republicana representativa, como lo establece esta Constitución y en el ejercicio de su soberanía no reconoce más limitación que la Constitución Federal que ha jurado obedecer y las leyes y disposiciones que en su conformidad se dictaren" (grifo nosso). Apesar de reconhecer a limitação da Constituição Federal, o texto faz uso do vocábulo "soberania", registrando uma quase que isonomia entre ente federal e federado.

${ }^{9}$ Esta perspectiva pode ser vista tanto em Colacrai e Zubelzú (2004) quanto em Colacrai (2005). Estes artigos fornecem muitos elementos importantes para se compreender a atuação de Províncias argentinas ante o exterior.
} 
assinado o tratado de integração regional entre Córdoba e Santa Fé, o qual é integrado logo após por Entre Ríos.

A segunda forma a ser destacada corresponde aos Comitês de Fronteira, que atuam como instrumento para reforçar a cooperação transfronteiriça. Estes Comitês contribuem para uma reavaliação desta cooperação transfronteiriça, reduzindo situações de tensão e má percepção (Colacrai, 2005, p. 14). São concebidos como organismos capazes de promover soluções para problemas oriundos do tráfico, assim como incentivar iniciativas de cooperação e de caráter integracionista. Os tópicos de comunicação e infraestrutura também são contemplados. Os Comitês de Fronteira que se desenvolvem mais são para a interação com províncias chilenas; e não com aquelas dos parceiros mercosulinos.

Por fim, e como procedimento mais frequente, as Províncias assinam acordos que incluem basicamente interesses econômicos e sociais que os governos provinciais preferem gerenciar diretamente. A Dirección de asuntos federales pode fornecer assessoria aos poderes provinciais sobre a assinatura de acordos externos em coordenação com o serviço consular argentino.

\section{A questão das Papeleras ${ }^{10}$}

Desde 1987, o Uruguai implementa uma política de incentivos ao reflorestamento industrial com vistas a atrair a indústria papeleira internacional. Em resposta a esta política, em 2002, a empresa espanhola Ence, que já vinha trabalhando com o reflorestamento havia alguns anos, apresenta proposta de construção de uma fábrica de celulose ao governo uruguaio, perto ao acesso à Ponte Libertador San Martín, que liga o Uruguai à Argentina, e em frente à cidade entrerriense de Gualeguaychú.

\footnotetext{
${ }^{10}$ Esta parte foi basicamente inspirada no artigo de Magalhães (2006), que faz um histórico muito bom da questão, junto com a consulta de jornais (La Nación, Clarín e Página 12).
} 
Antes da aceitação formal do projeto pelo governo uruguaio, o governo argentino invoca um estatuto de regulação do uso das águas do Rio Uruguai, assinado por ambos os países em 1975. O Estatuto do Rio Uruguai prevê o gerenciamento comum do rio através da Comissão Administradora do Rio Uruguai (Caru), que é composta por diplomatas dos dois países. Segundo o Estatuto, antes de toda obra que pode ter impacto sobre a navegação no rio, o outro país deve receber informações e efetuar consultas. Neste caso, a chancelaria argentina decide solicitar informações sobre o possível impacto ambiental que a fábrica de celulose pode provocar, buscando uma solução mais técnica para o caso. Neste momento e partindo do pressuposto de que as usinas papeleras seriam contaminantes, inicia-se, se bem que com baixa intensidade, um protesto por parte de setores da sociedade civil da cidade de Gualeguaychú contra a construção da usina.

86 Em outubro de 2003, o governo uruguaio dá sua autorização formal para a Ence tocar adiante a obra, o que serve de estopim para a ampliação do movimento gualeguaychen$s e .{ }^{11} \mathrm{O}$ governo argentino, já sob a liderança de Néstor Kirchner, convoca a Caru com urgência e reclama o cumprimento das exigências do Estatuto. A chancelaria uruguaia envia para o governo argentino uma documentação entregue pela Ence que aponta os limites do impacto ambiental. A documentação é examinada por especialistas argentinos que identificam altos riscos de impacto ambiental e sugerem a utilização de uma tecnologia diferente que produziria menos danos ambientais, assim como maior controle por parte da Caru. Poucos meses depois, representantes do movimento organizado contra as papeleras entregam uma reivindicação contrária às obras ao presidente Kirchner.

\footnotetext{
${ }^{11}$ Um primeiro bloqueio da estrada que leva à ponte de San Martín deu-se neste momento.
} 
As negociações bilaterais experimentam então um aumento, até concluir-se que a Caru deveria ser responsável pelo monitoramento dos impactos ambientais produzidos pela obra de construção da fábrica, após o que, anuncia-se um programa comum sobre os termos de monitoramento das obras da Ence. Mas a proposta da empresa finlandesa Metsa-Botnia de construir uma segunda usina em local próximo jogou água no programa. Outra vez, o governo argentino solicita informações e consultas sobre o novo empreendimento e, outra vez, o governo uruguaio demora em dar resposta.

Esta situação provoca um aumento da oposição à construção das usinas papeleras por parte de setores da sociedade civil, que resulta na organização dos campos opositores que passam a se reunir e a se organizarem tanto a nível nacional quanto internacional. ${ }^{12}$ Esta oposição, com o apoio do governador de Entre-Ríos, Jorge Busti, começa a se materializar em ações públicas chegando ao ápice com o bloqueio do acesso à ponte de San Martín que liga Gualeguaychú a Fray Bentos, que ocorre diversas vezes de forma descontinuada durante 2005.

No início deste mesmo ano, o Ministério de Meio Ambiente uruguaio concede a autorização definitiva à Metsa-Botnia, o que foi considerado pelo governo argentino uma violação do estatuto do Rio Uruguai e provoca novo recrudescimento na ação coletiva de Gualeguaychú. ${ }^{13}$ As reivindicações do movimento, agora mais estruturado, são absorvidas pela política interna e os governos, tanto pro-

\footnotetext{
${ }^{12}$ Movimentos ambientalistas uruguaios e internacionais apoiaram a oposição ao projeto.

${ }^{13}$ Cabe ressaltar que, para o Uruguai, além das políticas de incentivo de reflorestamento florestal que já vinham sendo implementadas havia muitos anos, o impacto econômico do projeto foi estimado em 2,5\% do Produto Interno Bruto uruguaio de 2004, para cada ano de plena atividade. O impacto sobre o emprego seria também importante, assim como os benefícios para o fluxo comercial (Magalhães, 2006, p. 7).
} 
vincial quanto nacional, passam a assumir uma posição de compromisso com a causa. ${ }^{14}$

Com vistas à solução do impasse, em maio de 2005 é criado especialmente o Grupo Técnico Bilateral, com a tarefa de facilitar a troca de informações entre ambos os governos sobre o andamento das obras, assim como seu impacto sobre o meio ambiente do rio. O Grupo é composto por especialistas dos dois países, sob a coordenação dos Ministérios de Relações Exteriores, com um prazo de funcionamento de 180 dias. E, importante, no caso argentino conta com representantes do governo de Entre Ríos, assim como com representantes da sociedade civil organizados agora na Assembleia Ambiental de Gualeguaychu. ${ }^{15}$

Em junho de 2005, o governo da Província de Entre Ríos inicia pressões sobre o Banco Mundial e a Corporação Financeira Internacional (CFI), mostrando preocupação com o financiamento de um projeto com impactos ambientais duvidosos. ${ }^{16}$ Esta iniciativa fez as tensões se acirrarem e o que seria a primeira reunião do Grupo Técnico foi adiada. A opção pelo não entendimento já se faz sentir.

Durante o mês de agosto, uma comissão composta por assembleístas de Gualeguaychú e pelo governador Busti é recebida pelo presidente Kirchner e pelo chanceler Rafael Bielsa para colocar sua preocupação com a construção das usinas papeleras, pressionando o governo no sentido de maior envolvimento com o tema. Em setembro deste ano, o governador Jorge Busti protocola na Comissão Interame-

\footnotetext{
${ }^{14} \mathrm{O}$ governador Jorge Busti, do partido peronista, mas que havia apoiado Menem nas eleições de 2003, passa a defender inteiramente e respaldar, em termos práti$\cos$, a posição do movimento de oposição às papeleras.

${ }^{15}$ Organização Não Governamental criada neste mesmo ano para coordenar a oposição às usinas papeleras, que aglutina pessoas em destaque que manejam a agenda da cidade, do governo ou da oposição.

${ }^{16} \mathrm{O}$ representante argentino no Banco Mundial apoia a solicitação de Busti. A Chancelaria, por seu turno, fica reticente. A CFI dá o aval para o empréstimo dos bancos, o que supõe um selo de qualidade ambiental.
} 
ricana de Direitos Humanos da Organização dos Estados Americanos uma queixa contra o Uruguai, acusando-o de violar a Convenção Interamericana de Direitos Humanos. Paralelamente - e acompanhada de uma estratégia mobilizadora por parte do governo de Busti - a Assembleia Ambiental volta a bloquear a ponte de San Martin, de ligação com o Uruguai, e exercer uma pressão sobre o chanceler Rafael Bielsa.

Em resposta à solicitação do governo Busti, representantes liderados pela Ombudswoman do Banco Mundial vão examinar o projeto na região e se reúnem com o próprio governador e com ambientalistas de Gualeguaychú, comprometendo-se a fazer um estudo mais aprofundado do possível impacto ambiental. Mas, em final de dezembro, informe preliminar do Banco afirma que as papeleras cumpririam os requisitos técnicos. Busti qualifica o informe de tendencioso, enquanto representantes do governo também mostram sua insatisfação com o informe. ${ }^{17}$

Neste mesmo período, surgem matérias de jornal especulando sobre a existência de tentativas anteriores do governo de Busti de atrair a construção de usinas papeleras para Entre Ríos. ${ }^{18}$ Os governadores de Misiones e Corrientes manifestam posição a favor da construção das usinas papeleras no Uruguai e acusam Busti de fazer uso político da questão. ${ }^{19}$

\footnotetext{
${ }^{17}$ Ver em La Nación, 20/12/2005, Primer apoyo a Uruguai por la construcción de las Papeleras (p. 1) e Profundo malestar en la Casa Rosada (p. 10). Em abril de 2006, o relatório definitivo confirmou a visão dos estudos anteriores.

${ }^{18}$ Divulgados arquivos de diários de Entre Ríos que contam como o governo Busti havia tentado atrair a construção de duas papeleras para a Província em sua primeira gestão, em 1996. Neste momento, Busti teria recebido empresários estrangeiros e assinado um decreto que estabelecia incentivos para a instalação de indústrias, inclusive papeleras. Mas, ao mesmo tempo, Busti teria falado de proteções ambientais. Busti negou as informações. (22/11/2005)

${ }^{19} \mathrm{Em}$ Misiones funcionam 3 indústrias do ramo de celulose, e o governador de Corrientes especula a possibilidade de implantar uma indústria também nesta Província $(24 / 11 / 2005)$.
} 
O ano de 2005 é ano eleitoral para o Poder Legislativo na Argentina, e a vinculação entre as críticas ao projeto das papeleras e a política nacional toma corpo. Os dividendos políticos podem atender tanto aos interesses do governador Busti, como do Presidente Kirchner, que está em campanha eleitoral. ${ }^{20}$ As críticas assumem assim um caráter nacionalista. Em reunião com Busti, Kirchner afirma que a questão das papeleras é uma "causa nacional". No entanto, com o fim das eleições o governo mantém a mesma posição. ${ }^{21}$

Por outro lado, e um pouco contra a posição mais frequente de criticar os danos ambientais a serem provocados pelas usinas papeleras, estudiosos e ambientalistas criticam a ausência de uma política ambiental na Argentina, manifesta em diferentes situações em que o meio ambiente é posto em risco, assim como de interesse do Legislativo sobre o tema em termos gerais. A Secretaria de Meio Ambiente, criada em 1973, é fraca e está integrada ao Ministério da 90 Saúde. ${ }^{22}$

A chancelaria uruguaia, por seu turno, decide apelar para a solução do litígio nos marcos do Mercosul. Optou por invocar o artigo $1 .^{\circ}$ do Tratado de Assunção, que obriga os Estados-membros a manterem abertos os canais de circulação de pessoas e mercadorias no interior do bloco.

Em dezembro, o chanceler Jorge Taiana reúne-se com autoridades entrerrianas e representantes da Assembleia Ambientalista de Gualeguaychú e define uma posição oficial do governo argentino em relação ao tema. ${ }^{23}$ Em seguida,

\footnotetext{
${ }^{20} \mathrm{~A}$ utilização por parte dos meios políticos de temas de política exterior para conseguir frutos na política interna é muito frequente.

${ }^{21}$ Palermo (2006) contradiz a versão de que a posição do governo teria um intuito eleitoreiro. Segundo o autor, apesar de ser um momento propício para mudanças, a política do não entendimento com o Uruguai na questão foi mantida.

${ }_{22}$ Ver Reboratti, C., "La falta de una política ambiental". Clarín, 11/11/2005; e Bullrich, L., "Critican el desinterés y la incoerencia del discurso oficial". La Nación, 14/6/2006.

${ }^{23}$ Ver, La protesta argentina no tiene ningún fundamento, p. 12, 28/12/2005.
} 
a chancelaria argentina notifica a existência de uma controvérsia com o Uruguai, o que abre formalmente espaços para um eventual avanço no campo jurídico, que se traduz em um recurso à Corte Internacional de Justiça (CIJ).

No início de 2006, período de férias e muito movimento turístico sobretudo da Argentina para as praias uruguaias, os bloqueios agora às três pontes de ligação da Província de Entre Ríos com o Uruguai intensificam-se. Com a organização do bloqueio pela Assembleia Ambiental, este passa a ser levado adiante de forma intermitente. ${ }^{24}$

No final de janeiro de 2006, o Grupo Técnico encerra suas atividades sem emitir um parecer consensual. Os representantes da argentina seguem acusando o governo uruguaio de violar o Estatuto do Rio. No mesmo dia, a Câmara Legislativa de Entre Ríos aprova uma resolução que pede que a chancelaria encaminhe a queixa contra o Uruguai à Corte de Haia. O chanceler uruguaio declara que um recurso à Haia irá contra o Protocolo de Olivos, que prevê a convocação de um Tribunal ad hoc em caso de controvérsias comerciais no interior do bloco. O governo argentino insiste em definir a controvérsia como questão bilateral. ${ }^{25}$

Estas divergências se orientam para a diplomacia do bloco com os dois países buscando o apoio do governo brasileiro para suas respectivas posições. O governo uruguaio usa o contexto para vincular a opção do Mercosul como foro apropriado para dirimir a controvérsia com a necessidade de solucionar urgentemente os problemas de assimetrias no interior do bloco. O governo brasileiro evita compromissos com uma resposta lacônica. ${ }^{26}$

\footnotetext{
${ }^{24}$ Muitos artigos comentam a intensificação do bloqueio. Ver, por exemplo, Vecinos de Gualeguychú analizan plan de lucha con cortes prolongados. Página 12, 2/1/2006.

${ }^{25} \mathrm{~A}$ consulta à CIJ é prevista no Estatuto do Rio Uruguai em caso de não solução das desavenças entre as partes.

${ }^{26}$ Isto fortalece no interior do Uruguai os setores que são avessos ao Mercosul e mais favoráveis à assinatura do tratado de livre comércio que estava então sendo negociado com os Estados Unidos.
} 
Em fevereiro, os opositores em Gualeguaychú decidem bloquear as Pontes internacionais por tempo indefinido, impedindo a passagem de turistas e prejudicando a economia uruguaia. O governo uruguaio solicita que a Argentina - então presidente pro tempore do Mercosul - convoque o Conselho do Mercado Comum para discutir o problema. O chanceler argentino, Jorge Taiana, visando evitar que a contenda passe para a esfera regional, declara, diante de parlamentares, que o governo uruguaio vinha violando o Estatuto do Rio Uruguai.

Então foi a vez do governo uruguaio enviar para a OEA uma nota afirmando que a Argentina estaria violando a Convenção Interamericana de Direitos Humanos por bloquear o tráfego entre os países, insistindo na convocação do mecanismo de solução de controvérsias ad hoc do Mercosul para julgar a falta de ação do governo argentino ante o bloqueio exercido pelos ambientalistas de Gualeguaychú.

92 Montevidéu envia, igualmente, uma nota à Corte de Haia abrindo um precedente para ações posteriores. ${ }^{27}$

O governo argentino, por seu turno, dá sequência aos passos necessários para formalizar a queixa contra o Uruguai na CIJ e, em maio, o processo tem início, acusando o Uruguai de ter violado o Estatuto do Rio Uruguai, autorizando as obras para as usinas papeleras sem o consentimento do governo argentino. Solicita que a CIJ imponha uma medida para suspensão das obras até que a questão do impacto ambiental seja devidamente avaliada. Neste contexto, representantes de Entre Ríos são enviados a Haia para compor a delegação argentina.

O início do processo, em junho, com as audiências, desperta muito interesse por parte da imprensa, que o acompanha exaustivamente. $\mathrm{O}$ governo argentino convoca a popu-

\footnotetext{
${ }^{27}$ Segundo Palermo (2006), a cultura política e o ambiente institucional argentinos vêm permitindo a identificação do bloqueio de pontes que busca melhorar sua eficiência afetando o direito direto de terceiros como "normal y rotinario".
} 
lação a apoiar as demandas à CIJ. Um evento de apoio é organizado em Gualeguaychú logo depois do bloqueio ser suspenso, com a presença de diversos governadores, ministros e parlamentares governistas.

A questão das papeleras já havia fartamente ultrapassado a esfera regional e tornado-se uma questão nacional. Um tema de política externa - ou política regional - era instrumentalizado em função da cultura política interna. As iniciativas políticas regionais, porém, seguem adiante. Entre elas, o governador Busti denuncia, como cúmplice da ditadura, o cônsul uruguaio designado para atuar em Gualeguaychú. ${ }^{28}$ Em seguida, envia representantes a Bruxelas para exporem o problema das papeleras a membros do Diretório Geral de Relações Exteriores da Comissão da União Europeia. O presidente Kirchner, por seu turno, concentra o discurso proferido na Cúpula União Europeia - América Latina e Caribe, que tem lugar em maio, em Viena, na questão ecológica e critica a transferência de empresas poluidoras da Europa para América Latina tomando como exemplo o caso das usinas de celulose.

A resposta uruguaia na CIJ, por seu turno, buscou diminuir o impacto ambiental das papeleras e ressaltar o retrocesso econômico que a interrupção nas obras iria causar. Em julho, a CIJ se manifesta sobre a solicitação argentina afirmando não ser provado que as obras causariam o impacto ambiental sugerido pelo governo nacional. Mas responsabilizou o Uruguai por eventuais danos, assim como eventual paralisação futura das obras, caso houvesse danos ambientais.

A decisão da CIJ não arrefeceu a disposição do governo argentino pelo enfrentamento no campo jurídico. Os movimentos opositores de Entre Ríos voltaram a exercer

\footnotetext{
${ }^{28}$ Arisbel Arnoldo Arocha Moreno havia sido diplomata em Buenos Aires durante o governo militar denunciado frente a ao juiz federal como colaborador da ditadura em seu país. Contactos con Uruguai por un cónsul polémico. La Nación, 15/6/2006. Afinal, o diplomata não foi enviado.
} 
pressões por uma solução urgente, e o governo argentino - junto com o governador Busti - buscou articular com os assembleístas uma posição jurídica comum para seguir o litígio em Haia. ${ }^{29}$ Este movimento resultou na formação de uma comissão na chancelaria que contou com a participação, entre outros, de quatro advogados indicados pela Assembleia Ambientalista e por funcionários de Entre Ríos com este objetivo. Retoma também as pressões sobre o Banco Mundial e a CFl com vistas a bloquear as linhas de crédito das empresas papeleras. Por fim, o fracasso em Haia resultou na saída de um diplomata de carreira da presidência da Caru para dar lugar a um político, ex-governador de Entre Rios. ${ }^{30}$

Adiante da disposição de continuidade do governo argentino e dos novos bloqueios de estradas, o governo uruguaio determinou a continuação do processo contra a Argentina na esfera do Mercosul por ela não tomar medidas apropriadas para coibir os impedimentos à livre circulação.

94 Como resposta ao Tribunal Arbitral, a Chancelaria argentina fez referência à "liberdade de expressão e manifestação" prevista na Constituição Nacional como justificativa para sua complacência ante os movimentos. Esta resposta gera uma série de críticas de juristas e setores da oposição.

Em agosto, o chanceler uruguaio entrega à chancelaria argentina uma proposta de monitoramento conjunto das obras e gestão das usinas papeleras, que é rejeitada pelo governo Kirchner, temendo reações contrárias do movimento de Entre Ríos. Inicia-se uma campanha na fronteira contra o turismo ao Uruguai, e o julgamento no Tribunal Arbitral do Mercosul da queixa uruguaia tem início.

\footnotetext{
${ }^{29}$ Diante da negativa dos assembleístas de irem a Buenos Aires, o chanceler Taiana vai a Gualeguaychú demonstrar a posição do governo de seguir com nova representação na CIJ.

${ }^{30}$ Os assembleístas acusavam o presidente anterior e não ter freado as obras das usinas papeleras desde a Caru. "Gestión clave de Taiana en Gualeguaychú". $L a$ Nación, 27/6/2006.
} 
Em setembro o Tribunal Arbitral do Mercosul faz pública sua opinião favorável ao Uruguai, aceitando que o movimento de assembleístas havia perdido a legitimidade ao afetar o direito de outros de transitar e exercer o comércio em uma estrada internacional, causando prejuízo a um Estado membro do Mercosul, e que o governo argentino havia sido omisso perante os bloqueios. ${ }^{31}$ Os assembleístas fazem uma passeata na estrada de ligação e iniciam uma campanha contra o veraneio no Uruguai.

No final do mês, a empresa espanhola Ence comunica ao governo uruguaio que o projeto de construção da usina será suspenso por questões industriais e que se buscará outra região do país para instalá-lo. ${ }^{32}$ Em seguida, o Banco Mundial divulga um relatório encomendado pela CFI que descarta a possibilidade das papeleras produzirem um impacto ambiental significativo. Os assembleístas reagem fechando as ligações desde Gualeguaychú e Colón no fim de semana seguinte, embora o governador Busti e o governo nacional, desta vez, tenham tentado inutilmente dissuadir os assembleístas sugerindo que a disputa ficasse nos marcos do direito supranacional. ${ }^{33}$ Diante dessa diferença de posições, os advogados representantes dos assembleístas abandonam a comissão que discutia o tema na sede do governo nacional.

\section{Tendência diplomática ou consortium pontual?}

A crise das papeleras encerra alguns traços que assinalam, concretamente, como o fundamento da ação externa do Estado-nacional se transforma. Ela também reflete que o tipo de estrutura desse Estado se mostra como uma variável

\footnotetext{
${ }^{31}$ Ver "Los principales puntos del fallo". La Nación on line, 6/9/2006.

${ }^{32}$ A direção da Ence alega que a proximidade entre as duas fábricas prejudicaria o seu desempenho.

${ }^{33}$ A sentença do Tribunal Arbitral supôs que os bloqueios já teriam acabado. Ver "Fin de semana con cortes en Entre Rios". La Nación, 11/10/2006; e "Con críticas al gobierno, volvió el corter de ruta en Gualeguaychú”, Clarin, 14/10/2006.
} 
relevante para a definição do modus operandi de sua inserção internacional. Os sistemas políticos da Argentina e do Uruguai são distintos. Enquanto o primeiro resulta da sedimentação de um processo genuíno de federalização; o segundo reflete um relativo monolitismo concentrado. Ambos, porém, possuindo capitais nacionais hipertrofiadas, tanto no que diz respeito ao poder político, quanto no que tange à capacidade econômica: a zona metropolitana de Buenos Aires encerra em seu interior em torno de 33\% da população nacional (Nickson, 2005, p. 97). Apesar de as potencialidades de mobilização social de Argentina e Uruguai não poderem ser vinculadas única e diretamente ao caráter federal ou não do arranjo institucional do Estado, é razoável inferir que os mecanismos descentralizadores estimulam a ação das unidades subnacionais em diversas áreas. Principalmente quando esses mecanismos são dotados de uma conotação política proeminente, como no caso argentino,

96 em que as províncias gozam, nessa seara, de status privilegiado, tendo legalmente vasta margem de manobra.

Ora, o que se observa é que na disputa das papeleras, a contenda se estabelece entre, de um lado, o Estado uruguaio, que concentra um maior poder de decisão no caso, e, do outro, um elusivo amálgama formado pelo governo nacional, o governo de Entre Ríos e setores da sociedade civil. ${ }^{34}$ Considerando a paradiplomacia como um epifenômeno no quadro uruguaio e focando na problemática da questão subnacional argentina, a rationale desse amálgama parece repousar sobre três fatores basilares: (i) a utilização coerente do regime internacional que rege as questões ecológicas; (ii) a capacidade de Entre Rios de mover uma ação coletiva paroquial conjugando interesses governamental e não governamental; (iii) a habilidade do governo federal

\footnotetext{
${ }^{34}$ Cabe lembrar que, neste caso, do lado do Uruguai, o governo nacional concentrou as decisões e ações referentes ao tema.
} 
de se apropriar do mote do empreendimento infra-estatal, subscrevendo-o internacionalmente.

O regime internacional, ${ }^{35}$ que tem balizado o uso do meio ambiente (Caldwell, 1996, p. 13), tem sido um dos mais ativos no cenário progressivo de globalização. Ele encerra forte potencial redutor de diferenças sociais, ou seja, é dotado de capacidade de despojar o cidadão de seu registro nacional, tornando-o simplesmente ser humano e, nessa condição, passível de perecer em face das reações nefastas da natureza contra as agressões que expia. A natureza, na verdade, intermedeia uma interdependência forçada entre atores assimétricos que zelam pelas suas respectivas sobrevivências. A Conferência de Estocolmo em 1972, a ECO-92 e o Protocolo de Kyoto são, por exemplo, mecanismos visíveis que resultam do esforço geral desses atores que buscam praticar um desenvolvimento sustentável, capaz de garantir a vida no longo prazo. Todavia, esses mecanismos são apenas alguns dentre uma miríade bem mais extensa. Como sublinha Greene (2006, p. 462), no 2000 já havia em torno de 130 acordos multilaterais sobre meio ambiente, ao lado de centenas de outros bilaterais. Muitos são simbólicos ou débeis, sem impactos reais no comportamento dos atores ou na questão por eles tratada. Entretanto, muitos deles são efetivos no sentido de mudar comportamentos de acordo com seus objetivos e enfrentar o problema para o qual são criados.

Por outro lado, o tema do meio ambiente tem se amoldado bem às demandas objetivas e pontuais da paradiplomacia, porquanto é marcado por uma participação e comprometimento significativo de atores não governamentais. Como afirma Keating (2004, p. 11): "a paradiplomacia é

\footnotetext{
35 "Regimes podem ser definidos como conjuntos de princípios, normas, regras e procedimentos de tomada de decisão, implícitos ou explícitos, em torno dos quais as expectativas dos atores convergem numa dada área das relações internacionais" (Krasner 1995, p. 1).
} 
também caracterizada por um alto grau de envolvimento da sociedade civil e do setor privado". Na verdade, desde sua aparição no cenário internacional, a questão do meio ambiente caracteriza-se por um tratamento político que coaduna a ação estatal com iniciativas outras, tocando tanto esferas privadas, como as das organizações não governamentais, quanto as públicas de nível supra e subnacional, como as das organizações regionais internacionais (ORIs) ou organizações regionais infraestatais (ORIEs).

O que se constata é que, dado o federalismo ${ }^{36}$ praticado pela Argentina, pode-se perceber na relação entre o governo central e o governo de Entre Ríos uma incipiente constituent diplomacy, catalisando e mobilizando a ação da sociedade civil local, concretizada, no caso das papeleras, na Assembleia Ambientalista. Configura-se, assim, uma situação rudimentar de perforated sovereinty (Duchacek, 2001, p. 3):

"à medida que as fronteiras [...] transformaram-se em fator de integração econômica, social e cultural, estimularam-se relações recíprocas e apresentaram-se novas necessidades institucionais" (Vigevani, 2006, p. 128).

O que surpreende, entretanto, é que, no caso específico das papeleras, essas iniciativas de constituent diplomacy e interação entre regiões transfronteiriças sejam resultantes de uma situação de conflito e não de cooperação transfronteiriça. Ao contrário da maioria de exemplos de atuação de atores subnacionais nas relações exteriores e dos Comités Comitês de Fronteira, em lugar de tentativas de cooperação o que caracteriza a ação destes atores é o enfrentamento.

\footnotetext{
36 "Nesse estudo, federalismo significa uma democracia plural onde dois conjuntos de governos legislam e administram dentro de suas separadas mais interconectadas esferas de jurisdição" (Duchacek, 2001, p. 03).
} 
O governo de Entre Ríos e a municipalidade de Gualeguaychú capitaneiam um movimento contestatório contra o Uruguai que se manifesta em uníssono com o forte apelo internacional pela proteção da natureza. Esses entes federados ecoam uma demanda social paroquial de cidadãos que se sentem diretamente ameaçados pela ação permissiva de um Estado vizinho no que concerne à instalação de empresas multinacionais que, segundo eles, atuarão como agentes poluidores do meio ambiente. A simbiose entre sociedade civil e poder local dá-se em consequência dos pays-offs oferecidos a esse último, que vê nesta iniciativa a possibilidade de conquistar votos e, consequentemente, alargar o horizonte de permanência no comando político. Além disso, o evento oferece outra possibilidade importante: permitir que o ator subnacional opere como consciência nacional, vigorando a sua posição na cartografia de poder da federação, assim como no seu entorno mais imediato, a saber: o Mercosul $^{37}$. Ao que parece, até o momento, os custos com a ação coletiva perpetrada por Entre Rios, Gualeguaychú e a Assembleia Ambientalista têm sido compatíveis com a expectativa de ganhos por parte de diferentes atores subnacionais e nacionais.

O problema das papeleras, de fato, foi identificado com uma causa nacional, assim como adotado totalmente pelo governo Kirchner. Palermo (2006) aponta a existência da cultura de um "nacionalismo territorialista":

“[marcada pelo] territorialismo, a unanimidade, a fé no potencial regenerativo de uma causa nacional e, especialmente, a noção vitimista de despojo, e que afeta diferentes dimensões da sociedade civil gualeguaychense ao governo nacional".

\footnotetext{
37 "Em suma, o custo (C) será uma função da taxa ou nível (T) no qual um bem coletivo é obtido $[\mathrm{C}=\mathrm{f}(\mathrm{t})$ ], e as curvas de custo médio terão a forma convencional de U" (Olson, 1965, p. 22).
} 
Ora, a reação do governo de Kirchner segue a lógica da reapropriação de um empreendimento com sólido apelo político interno e externo. Neste primeiro nível, o episódio das eleições legislativas em 2005 muito contribui para acelerar e galvanizar tal reapropriação. A bandeira ecológica é, pois, encampada com tenacidade no plano nacional, buscando remediar uma situação de fato marcada por políticas públicas débeis, assim como por instituições com pouca autonomia nesse terreno do meio ambiente. Por outro lado, no patamar externo, o governo federal trata de assegurar suas prerrogativas constitucionais, assumindo a coordenação das negociações com os atores estrangeiros, deixando clara a proeminência de sua atuação. Sem que isso signifique necessariamente exclusão de parcerias com os agentes subnacionais ou com a sociedade civil, mas apenas uma límpida afirmação de sua vocação de liderança nas relações internacionais.

100 O caso das papeleras parece envolver, em parte, o que em 1968 Garret Hardin chama de tragedy of the commons. Não no seu sentido primeiro de exaustão do bem comum no longo prazo, revelando uma racionalidade suicidária de pequeno alcance; porém, revelando, dentro do novo script cognitivo internacional, uma preocupação menos imediata e compromissada com a preservação desse bem que, nessa conjunção, se constitui no meio ambiente. Claro que os atores envolvidos têm ganhos e perdas diferenciadas, as papeleras, em princípio, podendo prejudicar ambas as partes, mas beneficiando, essencialmente, o Uruguai. A Província de Entre Ríos sofre também os impactos sociais e ambientais negativos próprios da iniciativa e sem compensações, enquanto os trade-off cabem somente ao Uruguai. Segundo Palermo (2006), trata-se de uma situação em que uma das partes - Uruguai - concentra o poder de decisão e, na ausência de mecanismos supra ou intergovernamentais próprios de regulação, a parte beneficiada tem poucos 
incentivos para negociar, enquanto a outra tende a usar recursos muitas vezes não previstos pelas regras preestabelecidas. ${ }^{38}$

Entretanto, o que chama atenção é que, perpassando essa relação, há o fato de se ter dois níveis não estatais stricto sensu, o infraestatal e o supraestatal, participando de maneira não desprezível na configuração da cartografia de poder estabelecida. Como assinala Ostrom (1990, p. 1):

"O que se pode observar no mundo, contudo, é que nem o estado nem o mercado são uniformemente bem-sucedidos a fim de sustentar o uso produtivo de sistemas de recursos naturais no longo prazo. Além disso, comunidades de indivíduos têm confiado em instituições que não lembram nem o Estado nem o mercado para governar alguns sistemas de recursos com razoáveis graus de sucesso durante longos períodos de tempo".

Ou seja, a administração de um common-pool resource empenha uma combinação variável de elementos reguladores que compreendem mais ou menos: mercado, Estado, Organizações Internacionais, ORIs, ORIEs, sociedade civil e ONGs. ${ }^{39}$ Aparentemente não existe uma combinação ótima a ser empregada de forma sistemática, mas tão-somente um conjunto de soluções que são forjados em função de variáveis estruturais e conjunturais do caso em questão. Neste caso, a ausência desta combinação fica visível.

\footnotetext{
${ }^{38}$ Segundo o autor, o conflito pode estar inscrito em um abuso de confiança por parte do Uruguai que, em função das particularidades de sua relação com a Argentina, presume que as represálias que pode vir a sofrer são limitadas.

39 "O termo common-pool resource se refere a um recurso natural ou produzido pelo homem que seja suficientemente grande para tornar custosa (mas não impossível) a exclusão de potenciais benificiários que desejem se favorecer do seu uso" (Ostrom, 1990, p. 30).
} 
Essa zona cinzenta marcada por amalgamações $a d$ hoc remete à reflexão em torno da caducidade (ou não) do conceito de soberania dos Estados. Historicamente, como consigna Kritsch (2002, p. 534):

"Entre o século XI e inícios do XIV [...] juristas, teólogos e filósofos fixaram as principais teorias a respeito da autoridade do príncipe [...]. Passavam a estar disponíveis, portanto, em matéria doutrinária, todos os elementos indispensáveis à consagração de um novo conceito de lealdade, aquele necessário à consolidação jurídica do Estado moderno, que teria na noção de soberania, fosse ela localizada no povo ou no governante supremo, um de seus principais atributos".

Entretanto, a ubiquidade do poder territorial desse Estado foi se transformando, assumindo um caráter mais 102 funcional. Isto é, com dificuldades para responder a um crescente número de demandas - cada vez mais complexas - oriundas da variedade de atores endógenos e exógenos, o Estado transfere, paulatinamente, algumas de suas competências. Evocando a ideia de interdependence sovereignty, Krasner (2001, p. 19) lembra que os Estados não conseguem muitas vezes regular intercâmbios transfronteiriços de bens, capitais, pessoas ou ideias; e que atividades que tradicionalmente foram reguladas pelos governos como política monetária, conhecimentos e saúde pública não podem mais ser por eles controladas em função do mercado internacional de capitais, da internet e dos movimentos populacionais, respectivamente. Essa soberania, interdependente, por se encontrar alijada de sua capacidade de controle, fundamenta-se numa modalidade de compromisso que pode ser qualificada como pareto-improving. Isso significa que o Estado decide, voluntariamente, renunciar a parte de suas prerrogativas em função de que flexibilizar 
os princípios do modelo de soberania estatal é mais atrativo do que não fazê-lo. ${ }^{40}$

A ação da província de Entre Rios no quadro da Argentina e de ambos diante do Uruguai alude, atualmente, a uma consorciação pontual de interesses; mas igualmente ela confirma uma tendência de contração do Estado que, de uma maneira ou de outra, aumenta a margem de manobra dos entes subnacionais, estimulando o incremento da paradiplomacia. Notadamente no que diz respeito à sua vertente interna, aquela derivada do lado cooperativo do federalismo argentino que, como no caso dos Länder alemães, pode migrar de uma situação mais limitada de transborder regional para-diplomacy, que se presta bem para questões do tipo common-pool resource, para um grau mais dilatado de global para-diplomacy, envolvendo uma quantidade maior de atores e esferas de atuação (Duchacek, 2001, p. 19).

Por outro lado, há que se anotar o papel pouco ativo do Mercosul no processo de negociação entre as partes envolvidas no conflito das papeleras. Suas instituições parecem não ter força suficiente para embargar e resolver a contenda, tendo ela desembocado em fórum de instituições internacionais de resolução de controvérsias. É verdade que o Mercosul contribui indiretamente na condição de balizador da ação do Estado e, também, como instigador das ações subnacionais, como no caso da criação do fórum de municípios, intendências, províncias e estados. Todavia, o Protocolo de Olivos parece ter atuado de forma marginal, contribuindo para uma redução de sua própria credibilidade e, por conseguinte, da do Mercosul. ${ }^{41}$ Neste caso, não existem

\footnotetext{
40 "[...] Isto é, eles fazem, no mínimo, um partido melhor sem tornar nenhum outro pior. Governos não são obrigados a aceitar estes acordos. Eles entram voluntariamente porque comprometer os princípios do modelo do Estado soberano é mais atrativo do que honrá-los" (Krasner, 2001, p. 23).

${ }^{41}$ O Protocolo de Olivos, assinado em 2003, instituiu os mecanismos de solução de controvérsias no interior do bloco, definiu os procedimentos de composição do Tribunal Arbitral ad hoc e de cumprimento dos seus laudos, assim como definiu sobre a constituição do Tribunal Permanente de Revisão.
} 
instituições supranacionais com competência e enforcement que garantam o cumprimento de determinadas normas (Palermo, 2006).

O Estado aparenta ter dificuldade na construção de um modus vivendi com a integração regional. Esse Estado procura por uma coerência que implique cessão de competência, sem que isso acarrete, contudo, um vácuo de poder que, ele próprio, prejudique o conjunto integracionista nas suas partes - entre elas os atores subnacionais - e no seu todo - em particular as instâncias supranacionais. Como afirma Hurrell (1995, 67):

"O regionalismo é frequentemente visto como uma alternativa para o Estado ou um meio para ir 'além do Estado' [...]. Além disso, as possibilidades de cooperação e integração regional parecem depender muito fortemente da coerência e da viabilidade dos Estados e de suas estruturas dentro de uma certa região".

\section{Conclusão}

O caso das papeleras revela-se um objeto de pesquisa que reflete os desafios enfrentados pelo Estado-nação na contemporaneidade. Esses desafios perpassam: (i) a questão da governance, a saber, uma forma ótima de gerenciar problemas socioeconômicos aliando, pari passu, mecanismos políticos de legitimidade e dispositivos econômicos eficientes, tudo isso amalgamando não apenas autoridades formais e nacionais imbuídas de poder coercitivo, porém, além delas, atores subnacionais, supranacionais e não governamentais; (ii) o tema da emergência paulatina de níveis concorrentes de gerenciamento da coisa pública em nível global, os agentes infraestatais despontando como vetor de legitimidade da ação cidadã, mesmo se esse gerenciamento compartilhado ainda se encontre restrito a temas específicos; (iii) o tópico relativo à ecologia - um desses temas específicos por 
excelência - e a seu regime internacional ativo balizando a tendência de reformulação da concepção do conceito de soberania, tanto no seu flanco interno, quanto no externo (Matteucci, 1983, p. 1.179).

Os limites intergovernamentais do Caru fomentam a capacidade de mobilização que, na Argentina, ocorre em cascata, partindo do epicentro Gualeguaychú, passando por Entre Rios e se alastrando rumo a Buenos Aires. E agregando nesse percurso um leque de atores políticos e agentes sociais de grande envergadura. Conjunturalmente, o fator eleição e, principalmente, a tendência ao nacionalismo territorialista, que caracteriza a cultura política argentina, estimularam a apropriação nacional dessa bandeira quase consensual que é a preservação do meio ambiente, sobretudo se ela envolve uma contraparte externa, cuja simples existência reforça o caráter pátrio da ação e, por conseguinte, as prerrogativas federais. Estruturalmente, todavia, o caso das papeleras galvaniza, se bem que de maneira ainda incipiente, a prática de uma constituent diplomacy, em que os entes subnacionais passam, de facto, e não apenas de jure, a fruir das prerrogativas previstas pelo pacto federal.

No entanto, apesar do papel menor desempenhado pelo Mercosul nessa crise, não se pode desconsiderar a função catalisadora que ele vem exercendo no que concerne ao rearranjo dos compromissos federais dos Estados-nações que o compõe. Ele atua - mesmo que, algumas vezes, de maneira simbólica ou no terreno da cognição dos tomadores de decisão (em todos os níveis e esferas) - como um elemento estimulador da ordem e da previsibilidade, fornecendo, em alguma medida, uma percepção de segurança que agrada, simultaneamente, aos atores endógenos e exógenos.

De qualquer forma, a questão não está terminada. A primeira reação do governo de Kirchner diante da disposição da Assembleia Ambiental de Gualeguaychú de fechar os acessos ao Uruguai foi de crítica à manutenção dos blo- 
queios. Mas pouco depois voltou atrás e reassumiu o enfrentamento com o Uruguai. O Banco Mundial aprovou definitivamente os créditos para a empresa finlandesa Botnia. E o Rei Juan Carlos II ensaiou alguns esforços no sentido de mediar a crise, mas sem êxito. Tudo indica que as interrupções no tráfego para o Uruguai podem seguir em 2007. Este caso segue sendo paradigmático e pode fornecer ainda elementos para se refletir sobre a atuação dos atores subnacionais tanto nos marcos de processos de integração quanto nas relações internacionais em geral.

\section{Marcelo de Almeida Medeiros}

é doutor em Ciências Políticas pelo Institut d'Études Politiques de Grenoble, França; professor associado de Ciências Políticas da UFPE

\section{Miriam Gomes Saraiva}

106 é doutora em Ciências Políticas pela Universidad Complutense de Madrid; professora adjunta do programa de PósGraduação em Relações Internacionais da UERJ

\section{Referências bibliográficas}

CALDWELL, L. K. 1996. International environmental policy: from the twentieth to the twenty-first century. Durham: Duke University Press.

COLACRAI, M. 2005. Sub-national governments and international relations. Cooperation or conflict with Nation-State? The case of Argentina. Paper presented in First Global International Studies Conference/World International Studies Committee, Istanbul, Bigli University, August, pp. 24-127.

.; ZUBELZÚ, G. 2004. "Las vinculaciones externas y la capacidad de gestión internacional desplegadas por las provincias argentinas en la última década. Una lectura desde las relaciones internacionales". In: VIGEVANI, T., WANDERLEY, L. E., BARRETO, M. I., MARIANO, M. P. (orgs.). A dimensão subnacional e as relações internacionais. São Paulo: Educ/Fundação Editora da Unesp/Edusc, pp. 313-344.

DUCHACEK, I. D. 2001. "Perforated sovereignty". In: MICHELMANN, H. J.; SOLDATOS, P. Federalism and international relations - The role of subnational units. Oxford: OUP. 
GREENE, O. 2006. "Environmental issues". In: BAYLIS, J.; SMITH, S. (ed.). The globalization of world politics. Oxford: OUP.

HARDIN, G. 1968. "The tragedy of the commons". Science, $\mathrm{n}^{\circ} 162$, pp. 1.243-1.248.

HURRELL, A. 1995. "Regionalism in theoretical perspective". In: FAWCETT, L.; HURRELL, A. (eds.). Regionalism in world politics. Oxford: OUP.

KEATING, M. 2004. "Regiones y asuntos internacionales: motivos, oportunidades y estratégias”. In: VIGEVANI, T., WANDERLEY, L. E., BARRETO, M. I., MARIANO, M. P. (orgs.). A dimensão subnacional e as relações internacionais. São Paulo: Educ/Fundação Editora da Unesp/ Edusc, pp. 49-75.

KEOHANE, R. O. 2001. "Governance in a partially globalized world", American Political Science Review, vol. 95, $\mathrm{n}^{\circ} 1$.

KINKAID, J. 2001. "Constituent diplomacy in federal polities and the Nation-State: conflict and Co-operation". In: MICHELMANN, H. J.; SOLDATOS, P. Federalism and International Relations - The role of subnational units. Oxford: OUP.

KRASNER, S. D. 1995. "Structural causes and regime consequences: regimes as intervening variables”. In: KRASNER, S. D. (ed.). International regimes. Ithaca: Cornell University Press.

. 2001. "Rethinking the sovereign state model". Review of International Studies, $\mathrm{n}^{\circ}$ 27. pp. 17-42.

KRITSCH, R. 2002. Soberania - A construção de um conceito. São Paulo: Humanitas/FFLCH-USP/Imprensa Oficial.

LIMA, M. R. S. de 2000. "Instituições democráticas e política exterior". Contexto Internacional vol. 22, $\mathrm{n}^{\circ}$ 2, Rio de Janeiro: IRI/PUC-RJ, jul./ dez., pp. 265-303.

MAGALHÃES, B. 2006. "O papel do Mercosul: a crise das papeleras e o processo de integração regional sul-americano”. Observador on Line, vol. $1, \mathrm{n}^{\circ}$ 6, Rio de Janeiro, Iuperj/Observatório Político Sul-Americano, agosto.

MATTEUCCI, N. 1983. "Soberania”. In: BOBBIO, N. et al. Dicionário de Política. Brasília: Ed. UnB.

MARIANO, M. P.; BARRETO, M. I. 2004. "Questão subnacional e integração regional: o caso do Mercosul”. In: VIGEVANI, T., WANDERLEY, L. E., BARRETO, M. I., MARIANO, M. P. (orgs.). A dimensão subnacional e as relações internacionais. São Paulo: Educ/Fundação Editora da Unesp/Edusc, pp. 21-47.

MEDEIROS, M. de A. 2006. "Dinâmica subnacional e lógica centro-periferia: os impactos do Mercosul na economia política dos estados de 
Pernanbuco, Bahia, São Paulo e Rio Grande do Sul”. Revista Brasileira de Política Internacional, Ano 49, nº 1. Brasília: Ibri, jan./jun., p. 224.

NICKSON, R. A. 2005. Local government in Latin America. Boulder/London: Lynne Rienner Publishers.

OLSON, M. 1965. The logic of collective action. Cambridge: Harvard University Press.

OSTROM, E. 1990. Governing the commons - The evolution of institutions for collective action. Cambridge: Cambridge University Press,

PALERMO, V. 2006. "La disputa entre Argentina y Uruguay por la contrucción de las procesadoras de celulosa en Fray Bentos”. Análise de Conjuntura OPSA, n. ${ }^{\circ} 11$. Rio de Janeiro: Iuperj/Observatório Político Sul-Americano, novembro.

VIGEVANI, T. 2006. "Problemas para a atividade internacional das unidades subnacionais - Estados e municípios brasileiros”. Revista Brasileira de Ciências Sociais, vol. 21, $\mathrm{n}^{\circ}$ 62, outubro.

, WANDERLEY, L. E., BARRETO, M. I., MARIANO, M. P. (orgs.). 2004. A dimensão subnacional e as relações internacionais. São Paulo: Educ/Fundação Editora da Unesp/Edusc. 


\section{OS ATORES SUBNACIONAIS NO MERCOSUL: 0 CASO DAS PAPELERAS}

MARCELO DE ALMEIDA MEDEIROS

MIRIAM GOMES SARAIVA

A constante e progressiva participação de governos subnacionais na esfera internacional chama atenção para uma nova dimensão das relações internacionais. As razões para esta implicação de governos subnacionais no cenário externo são vinculadas tanto às mudanças que ocorreram na esfera internacional, às reformas no interior dos Estados, quanto às modificações que têm lugar no comportamento dos governos subnacionais. A proposta deste artigo é analisar o conflito, resultante da construção de usinas Papeleras, de uma conjunção entre o governo nacional argentino, o governo provincial de Entre Ríos e setores da sociedade civil de Gualeguaychú contra o governo uruguaio. O caso das papeleras revela-se um objeto de pesquisa que reflete os desafios enfrentados pelo Estado-nação na contemporaneidade. Esses desafios perpassam: (i) a questão da governance, a saber, uma forma ótima de gerenciar problemas socioeconômicos aliando mecanismos políticos de legitimidade e dispositivos econômicos eficientes; (ii) o tema da emergência paulatina de níveis concorrentes de gerenciamento da coisa pública em nível global, os agentes infraestatais despontando como vetor de legitimidade da ação cidadã; (iii) o tópico relativo à ecologia e a seu regime internacional ativo balizando a tendência de reformulação da concepção do conceito de soberania, tanto no seu flanco interno, quanto no externo.

Palavras-chave: Papeleras; Paradiplomacia; Argentina; Uruguai; Mercosul. 